\title{
Study of $\mathrm{Pb}$ sources by $\mathrm{Pb}$ isotope ratios in the airborne $\mathrm{PM}_{10}$ of Zaragoza, Spain
}

\author{
María Teresa de la Cruz, ${ }^{a}$ Francisco Laborda, ${ }^{b}$ María Soledad Callén, ${ }^{* a}$ José Manuel López ${ }^{a}$ \\ and Ana María Mastral ${ }^{a}$
}

\author{
Received 23rd June 2009, Accepted 19th August 2009 \\ First published as an Advance Article on the web 11th September 2009 \\ DOI: $10.1039 / b 912274 \mathrm{e}$
}

Lead is a toxic trace element which produces harmful effects on human health, even at low concentrations, and it can be useful as ambient pollution tracer because the relative abundance of its four stable isotopes (204, 206, 207 and 208) depends on the emission source. This study was focused on the lead concentrations and isotope ratios in the $\mathrm{PM}_{10}$ of Zaragoza, in order to determine the main $\mathrm{Pb}$ pollution sources and to check whether the influence of the prohibition of leaded fuel was worthwhile. Two sampling campaigns from 2001 until 2004, the first one in which leaded gasoline was still effective and the second one with the phase-out, were carried out by using a high-volume air sampler able to trap the particulate matter equal to or less than $10 \mu \mathrm{m}\left(\mathrm{PM}_{10}\right)$ on Teflon-coated fibre glass filters. Firstly, the $\mathrm{Pb}$ concentrations for the two sampling campaigns were analysed by inductively-coupled plasma optical emission spectrometry (ICP-OES). No statistically significant decrease in the $\mathrm{Pb}$ average concentration was obtained from the first to the second sampling. Enrichment factors showed that anthropogenic sources were prevalent during both samplings, in particular during 2001-2002. Afterwards, only those samples with higher concentrations than the limit of quantification of $\mathrm{Pb}$ were analysed to determine the lead isotopic composition by inductivelycoupled plasma quadrupole mass spectrometry (ICP-QMS). To apply this analytical technique successfully, it was necessary to optimize the parameters affecting the measurement accuracy and precision. Differences were found regarding the lead isotope ratios for both periods finding that anthropogenic sources related to industrial processes were reflected on both campaigns. The gasoline contribution for the first campaign was $23 \%$ whereas for the second sampling this contribution was negligible, corroborating the success of the lead policies on the quality of the environment.

\section{Introduction}

Lead is a poisonous metal that can damage nervous connections (especially in young children) and cause blood and brain disorders. It is regulated by the Directive 2008/50/EC ${ }^{1}$ which estab-

${ }^{a}$ Instituto de Carboquímica (CSIC), Miguel Luesma Castán, 4, 50018 Zaragoza, Spain. E-mail: marisol@icb.csic.es; Fax: +34 976 733318; Tel: +34976733977

${ }^{b}$ Analytical Spectrometry and Sensors Group (GEAS), Environmental Sciences Institute (IUCA), University of Zaragoza, Pedro Cerbuna, 12, 50009 Zaragoza, Spain lishes a limit value of $0.5 \mu \mathrm{g} \mathrm{m}^{-3}$ for a calendar year. Although lead occurs naturally in the environment, most of the high levels found throughout the environment come from human activities. Before the use of leaded gasoline was banned, one of the main lead anthropogenic sources was related to traffic emissions. Many studies were dedicated to the evaluation of the impact of automotive lead on the environment and to the assessment of its absorption in the human population. ${ }^{2}$ During the 1970s, in particular in Europe and North America, actions were taken in order to abate the ambient pollution by lead because different studies showed that its concentration in remote areas and in

\section{Environmental impact}

Lead isotope ratios can be used as a fingerprint providing information on the relative importance of sources. Leaded fuel was one of the main sources producing high levels of lead in the air of major cities although significant reductions were achieved over recent years as the result of the European Directive 98/70/EC established on the $1^{\text {st }}$ of January 2000 with derogation until the $1^{\text {st }}$ of January 2002 for Spain. To get light on how relevant a directive can be on clean air, lead and lead isotope ratios were studied in the airborne $\mathrm{PM}_{10}$ of Zaragoza from 2001-2004 covering two sampling periods, the first one in which leaded fuel was still in use and the second one, once forbidden. The lead isotopic compositions were analyzed by inductively-coupled plasma quadrupole mass spectrometry (ICP-QMS) after optimizing the parameters affecting the measurement accuracy and precision. Differences were observed for ${ }^{208} \mathrm{~Pb} /{ }^{207} \mathrm{~Pb}$ and the ${ }^{206} \mathrm{~Pb} /{ }^{207} \mathrm{~Pb}$ ratios for both samplings with a predominance of industrial sources in the second sampling while, in the first one, characterized by lower isotope ratios, a mixture of leaded fuel $(23 \%)$ and industrial sources was obtained. 
human beings had significantly increased due to alkyl lead derivatives used as antiknock agents in gasoline. ${ }^{3}$ In order to reduce its concentration, a restrictive normative was promulgated, new non-leaded gasoline of high octane index was developed and the engine industry started using more resistant materials, which were not dependent on lead lubrication for its conservation. The European Union (Directive 98/70/EC) ${ }^{4}$ established the $1^{\text {st }}$ of January 2000, as a limit date, to remove leaded fuel from the market, although the European Commission conceded derogation to Spain, Italy and Greece until the $1^{\text {st }}$ of January 2002. Thus, until some years ago, emissions related to traffic represented the majority of sources of atmospheric $\mathrm{Pb} .^{5}$ That is the reason why the concentration of this element in the air has been reduced, although other natural sources (coming from the terrestrial crust) persist as much as anthropogenic ones, such as smelting, steel mills, incineration of residues, wood and coal combustion, resuspension of contaminated grounds and general production activities (production of paintings, chemical agents, welds, etc.). ${ }^{5,6}$ In addition, traffic continues introducing lead into the atmosphere since the gasoline that is used at the moment also contains variable amounts of this metal due to its presence in the crude (10-300 $\left.\mu \mathrm{g}^{-1}\right)$. Only its use as an additive is legislated. On the other hand, the concentration of $\mathrm{Pb}$ in the diesel emissions $\mathrm{s}^{5,7}$ is usually smaller than $1 \mu \mathrm{g} 1^{-1}$.

The $\mathrm{Pb}$, besides being a toxic trace element that produces wellknown adverse effects to a person's health at low concentrations, can also be used as a tracer of environmental pollution, since the relative abundance of its four stable isotopes of masses 204, 206, 207 and 208, also known as its isotopic signature, varies with the emission source. ${ }^{8}$ This is because the isotopes ${ }^{206} \mathrm{~Pb},{ }^{207} \mathrm{~Pb}$ and ${ }^{208} \mathrm{~Pb}$ are products of the decay of ${ }^{238} \mathrm{U}\left(\mathrm{T}_{1 / 2}=4.4710^{9}\right.$ years $)$, ${ }^{235} \mathrm{U}\left(\mathrm{T}_{1 / 2}=7.0410^{8}\right.$ years $)$, and ${ }^{232} \mathrm{Th}\left(\mathrm{T}_{1 / 2}=1.410^{10}\right.$ years $)$, respectively, while ${ }^{204} \mathrm{~Pb}$, which is not generated by radioactive decay, is used as a reference isotope.

In the studies on pollution by this metal, elementary analysis does not always provide information on its different origins whereas the measurements of the isotopic composition provide complementary information on the relative importance of each source. ${ }^{9}$ The lead isotopes present the advantage of not undergoing division on the part of any chemical or biological process. ${ }^{8}$ The environmental sources of lead are very varied and in order to use the isotopic signature as a discriminatory tool it is necessary that the isotopic ratios are different for each source. This paper has been focused on the $\mathrm{Pb}$ concentrations and its isotope ratios in order to deepen the knowledge of lead sources and to check whether the influence of the non-leaded gasoline was remarkable during the studied period. Firstly, and in order to achieve these aims, an optimization of the ICP-QMS parameters used to determine lead isotope ratios was performed.

\section{Experimental}

\subsection{Sampling program}

The study was performed in the city of Zaragoza (located in the North-East of Spain $\left(41^{\circ} 39^{\prime} 49.38^{\prime \prime} \mathrm{N} ; 0^{\circ} 53^{\prime} 16.68^{\prime \prime} \mathrm{W}\right)$ close to a heavy traffic motorway where several industrial parks are located. A GUV-15H Graseby Andersen High-Volume sampler with volumetric flow controlled system provided with a $\mathrm{PM}_{10}$ cut off inlet at $10 \mu \mathrm{m}$ was used (PTFE-coated, glass-fibre filters, $0.6 \mu \mathrm{m}$ pore size). ${ }^{10}$

Samples corresponding to two sampling campaigns were analysed. The first campaign was carried out from July 12th, 2001 to July 26th, 2002 on weekdays every two weeks. More intensive sampling dates: $11,12,13,14$ and $15^{\text {th }}$ March 2002, 18, 19, 20 and $21^{\text {st }}$ June 2002, 22, 23, 24 and 26th July 2002 were also collected amounting a total of 41 samples. The second campaign was performed every week from April 7th, 2003 to July 5th, 2004 collecting a total of 50 samples. Sampling time was $24 \mathrm{~h}$, yielding sample volumes among 1600 and $1700 \mathrm{~m}^{3}$. More details regarding sampling procedure can be found in previous publications..$^{9,11}$

\subsection{Determination of lead concentration}

One quarter of the filters was digested twice with concentrated $\mathrm{HNO}_{3}$ in a Teflon bomb according to the procedure previously published. ${ }^{10}$ The analysis of $\mathrm{Pb}$ was carried out by ICP-OES (JY 2000 Ultrace Horiba).

\subsection{Determination of lead isotope ratios}

The solutions from the acid digestion of the filters were diluted to a lead concentration of about $50 \mu \mathrm{g}^{-1}$ using $2 \%$ high-purity $\mathrm{HNO}_{3}$ (J.T. Baker). All materials used to prepare solutions and standards were pre-cleaned in $10 \% \mathrm{HNO}_{3}$ for 48 hours, rinsed in ultrapure water (Milli-Q) and oven-dried.

Lead isotope ratios were measured by ICP-QMS. A PerkinElmer Sciex model ELAN 6000 ICP mass spectrometer was used. The sample introduction system consisted of a cross-flow nebulizer and a double-pass Scott-type spray chamber. Optimized instrumental and data acquisition parameters are listed in Table 1.

The isotopic standard SRM 981 (NIST Common Lead Isotopic Standard) was used to calculate the dead time of the instrument and to correct mass discrimination effects. Dead time was measured according to the method described by Vanheunzen et al. $^{12}$ and loaded into the instrument software. External corrections due to mass discrimination of the spectrometer were

Table 1 Quadrupole ICP-MS instrumental and data acquisition parameters

Instrumental parameters

\begin{tabular}{ll}
\hline RF power & $1000 \mathrm{~W}$ \\
Argon flows & \\
External & $151 \mathrm{~min}^{-1}$ \\
Auxiliary & $1.21 \mathrm{~min}^{-1}$ \\
Nebulizer & $0.91 \mathrm{~min}^{-1}$ \\
Sample uptake rate & $1.2 \mathrm{ml} \mathrm{min}^{-1}$ \\
\hline
\end{tabular}

Data acquisition parameters
Measuring mode

Points per mass

Dwell time

Sweeps

Integration time per isotope

Settle time

Replicates
Peak hopping 1 $20 \mathrm{~ms}$ 1000 $20 \mathrm{~s}$

$3 \mathrm{~ms}$ 
performed by measuring a $50 \mu \mathrm{g}^{-1}$ solution of SRM 981 every four samples; an averaged correction factor calculated from two SRM 981 measurements was applied to the four samples measured between them. Mass bias in the range of $0.02-0.04 \%$ were obtained for the ratios ${ }^{206} \mathrm{~Pb} /{ }^{207} \mathrm{~Pb}$ and ${ }^{208} \mathrm{~Pb} /{ }^{207} \mathrm{~Pb}$. Internal correction by using the ${ }^{203} \mathrm{Tl} /{ }^{205} \mathrm{Tl}$ ratio of thallium spiked samples was also studied, although mass biases were higher than when using the external correction (Monna et al. ${ }^{16}$ ). The signals were further corrected for instrumental and procedure blanks, which were below $0.03 \mathrm{ng} \mathrm{ml}^{-1}$ of lead.

Current techniques for the measurement of lead isotope ratios are based on either thermal ionization mass spectrometry (TIMS) or inductively-coupled plasma mass spectrometry (ICPMS). TIMS can provide high precision data $(0.005-0.01 \%$ expressed as relative standard deviation (RSD)), although the technique requires the separation of lead from the sample matrix, involving longer sample preparation and data acquisition times than those for ICP-MS. In ICP-MS, precision with a single detector ranges from $0.1-0.5 \%$ for quadrupole mass spectrometers to $0.02-0.2 \%$ for double focusing sector field instruments, whereas precision as low as $0.002 \%$ can be obtained with multicollector sector field ICP-MS. ${ }^{13}$ Nowadays, quadrupole ICPMS instruments are available in most environmental laboratories and the performance of these instruments fulfills the requirements for lead environmental studies. ${ }^{14}$ Even so, the achievable precision can be improved by proper selection of the acquisition parameters. ${ }^{15}$ The optimized acquisition parameters listed in Table 1 provided relative standard deviations below $0.1 \%$ for isotope ratios involving the three most abundant lead isotopes $\left(0.05 \%\right.$ for ${ }^{206} \mathrm{~Pb} /{ }^{208} \mathrm{~Pb}$ and $0.07 \%$ for $\left.{ }^{208} \mathrm{~Pb} /{ }^{207} \mathrm{~Pb}, \mathrm{n}=10\right)$, around twice the theoretical attainable precision calculated by counting statistics. ${ }^{15}$ This performance is obtained by controlling the counting statistics through the integration time, working with the maximum number of sweeps of the instrument (1000) and a dwell time of 20 milliseconds, because no significant improvements were obtained at higher dwell times. The same integration time was selected for each isotope whatever their abundances; because no improvements were observed when integration times inversely proportional to the isotope abundance were used. ${ }^{16}$

\section{Results and discussion}

\subsection{Lead concentrations}

The lead concentrations higher than the quantification limit as well as the isotopic compositions are shown in Table 2 for the first and second sampling campaigns. The average $\mathrm{Pb}$ concentration for the first batch was $18.9 \mathrm{ng} \mathrm{m}^{-3}$ (41 samples) (Table 2) while this average value was slightly lower for the second batch, $13.0 \mathrm{ng} \mathrm{m}^{-3}$ (50 samples) although the difference was not statistically significant. For both samplings, no date exceeded the guide values established by the European Union ${ }^{1}$ and the World Health Organization (WHO).

Comparing with other data published in bibliography, the lead concentration was $21 \mathrm{ng} \mathrm{m}^{-3}$ over Dundee, $\mathrm{UK}^{17}{ }^{17} 150 \mathrm{ng} \mathrm{m}^{-3}$ over Mexico City, Mexico, ${ }^{18} 10-33700 \mathrm{ng} \mathrm{m}^{-3}$ over Cairo, Egypt, ${ }^{19} 27$, 128 and $200 \mathrm{ng} \mathrm{m}^{-3}$, respectively, over three sites in Korea. ${ }^{20}$ In general, lower concentrations of lead were found in Zaragoza when comparing with other countries, in particular Asian
Table 2 Lead concentration and lead isotope ratios for the dates analyzed in both campaigns

\begin{tabular}{|c|c|c|c|c|}
\hline Date & $\begin{array}{l}\mathrm{Pb} \\
\left(\mathrm{ng} / \mathrm{m}^{3}\right)\end{array}$ & $\begin{array}{l}\mathrm{Pb} \\
\left(\mathrm{ng} / \mathrm{mg} \mathrm{PM}_{10}\right)\end{array}$ & ${ }^{206} \mathrm{~Pb} /{ }^{207} \mathrm{~Pb}^{a}$ & ${ }^{208} \mathrm{~Pb} /{ }^{207} \mathrm{~Pb}{ }^{b}$ \\
\hline $12 / 07 / 2001$ & 13.78 & 0.31 & 1.1365 & 2.4075 \\
\hline $09 / 08 / 2001$ & 4.974 & 0.15 & 1.1423 & 2.4078 \\
\hline $23 / 08 / 2001$ & 23.82 & 0.39 & 1.1320 & 2.4050 \\
\hline 06/09/2001 & 14.03 & 0.34 & 1.1325 & 2.4043 \\
\hline $20 / 09 / 2001$ & 52.41 & 1.2 & 1.1515 & 2.4166 \\
\hline $04 / 10 / 2001$ & 49.93 & 1.1 & 1.1490 & 2.4160 \\
\hline $18 / 10 / 2001$ & 51.73 & 1.8 & 1.1371 & 2.4054 \\
\hline $30 / 10 / 2001$ & 42.08 & 0.40 & 1.1475 & 2.4068 \\
\hline $15 / 11 / 2001$ & 10.67 & 0.45 & 1.1360 & 2.4068 \\
\hline $29 / 11 / 2001$ & 7.301 & 0.23 & 1.1469 & 2.4166 \\
\hline $13 / 12 / 2001$ & 18.02 & 0.30 & 1.1345 & 2.4039 \\
\hline $27 / 12 / 2001$ & 5.866 & 0.14 & 1.1528 & 2.4170 \\
\hline $10 / 01 / 2002$ & 17.79 & 0.34 & 1.1330 & 2.4050 \\
\hline $24 / 01 / 2002$ & 9.643 & 0.28 & 1.1325 & 2.4050 \\
\hline $07 / 02 / 2002$ & 11.86 & 0.52 & 1.1481 & 2.4165 \\
\hline $11 / 03 / 2002$ & 63.91 & 1.2 & 1.1420 & 2.4111 \\
\hline $12 / 03 / 2002$ & 75.83 & 1.3 & 1.1403 & 2.4105 \\
\hline $13 / 03 / 2002$ & 29.51 & 0.66 & 1.1502 & 2.4195 \\
\hline $14 / 03 / 2002$ & 9.417 & 0.38 & 1.1409 & 2.4100 \\
\hline $15 / 03 / 2002$ & 32.37 & 1.1 & 1.1408 & 2.4113 \\
\hline $16 / 05 / 2002$ & 116.4 & 2.2 & 1.1455 & 2.4136 \\
\hline $30 / 05 / 2002$ & 47.43 & 1.1 & 1.1431 & 2.4127 \\
\hline $13 / 06 / 2002$ & 14.40 & 0.32 & 1.1573 & 2.4129 \\
\hline \multirow[t]{2}{*}{$21 / 06 / 2002$} & 23.47 & 0.37 & 1.1475 & 2.4195 \\
\hline & & Average & $1.1425 \pm 0.0072$ & $2.4109 \pm 0.0051$ \\
\hline \multicolumn{5}{|c|}{${ }^{a} \mathrm{RSD}=0.05 \%(\mathrm{SRM} 981, \mathrm{n}=10) .{ }^{b} \mathrm{RSD}=0.07 \%(\mathrm{SRM} 981, \mathrm{n}=10)$} \\
\hline Date & $\begin{array}{l}\mathrm{Pb} \\
\left(\mathrm{ng} / \mathrm{m}^{3}\right)\end{array}$ & $\begin{array}{l}\mathrm{Pb} \\
\left(\mathrm{ng} / \mathrm{mgPM}_{10}\right)\end{array}$ & ${ }^{206} \mathrm{~Pb} /{ }^{207} \mathrm{~Pb}$ & ${ }^{208} \mathrm{~Pb} /{ }^{207} \mathrm{~Pb}$ \\
\hline 07/04/2003 & 9.037 & 0.26 & 1.1567 & 2.4217 \\
\hline $21 / 04 / 2003$ & 11.04 & 0.51 & 1.1520 & 2.4227 \\
\hline $28 / 04 / 2003$ & 29.05 & 0.83 & 1.1560 & 2.4237 \\
\hline $05 / 05 / 2003$ & 6.308 & 0.26 & 1.1572 & 2.4256 \\
\hline $12 / 05 / 2003$ & 20.29 & 0.59 & 1.1576 & 2.4243 \\
\hline $19 / 05 / 2003$ & 9.435 & 0.27 & 1.1569 & 2.4233 \\
\hline $02 / 06 / 2003$ & 19.09 & 0.58 & 1.1479 & 2.4198 \\
\hline $09 / 06 / 2003$ & 43.23 & 0.90 & 1.1646 & 2.4398 \\
\hline $23 / 06 / 2003$ & 17.70 & 0.24 & 1.1499 & 2.4206 \\
\hline $14 / 07 / 2003$ & 8.124 & 0.13 & 1.1529 & 2.4211 \\
\hline $18 / 08 / 2003$ & 10.87 & 0.28 & 1.1539 & 2.4207 \\
\hline $09 / 12 / 2003$ & 9.985 & 0.28 & 1.1624 & 2.4256 \\
\hline $12 / 01 / 2004$ & 13.78 & 0.30 & 1.1526 & 2.4214 \\
\hline $16 / 02 / 2004$ & 7.704 & 0.23 & 1.1551 & 2.4247 \\
\hline $08 / 03 / 2004$ & 31.51 & 1.4 & 1.1629 & 2.4443 \\
\hline $29 / 03 / 2004$ & 6.793 & 0.86 & 1.1627 & 2.4299 \\
\hline $05 / 04 / 2004$ & 7.547 & 0.30 & 1.1566 & 2.4253 \\
\hline $19 / 04 / 2004$ & 36.83 & 2.1 & 1.1648 & 2.4469 \\
\hline $17 / 05 / 2004$ & 86.05 & 1.9 & 1.1656 & 2.4435 \\
\hline $24 / 05 / 2004$ & 75.97 & 2.2 & 1.1534 & 2.4234 \\
\hline $07 / 06 / 2004$ & 49.60 & 1.3 & 1.1658 & 2.4401 \\
\hline $21 / 06 / 2004$ & 39.07 & 0.99 & 1.1549 & 2.4220 \\
\hline \multirow[t]{2}{*}{ 05/07/2004 } & 0.6944 & 0.020 & 1.1597 & 2.4269 \\
\hline & & Average & $1.1574 \pm 0.0052$ & $2.4277 \pm 0.0086$ \\
\hline
\end{tabular}

countries. Nevertheless, atmospheric concentrations of $13 \mathrm{ng} \mathrm{m}^{-3}$ and $2.9 \mathrm{ng} \mathrm{m}^{-3}$ were also found in Mount Qomolangma, China in 2002 and 2000 although it corresponded to an area in which there was no pollution emission source surrounding the sampling site. ${ }^{21}$

\subsection{Enrichment factors}

Trying to obtain information on the anthropogenic or natural origin of sources for lead, the enrichment factors (EF) were calculated according to equation 1 : 


$$
\mathrm{EF}(\mathrm{Pb})=(\mathrm{Pb} / \mathrm{Fe}) \mathrm{PM} 10 /(\mathrm{Pb} / \mathrm{Fe}) \text { crust }
$$

In this work, $\mathrm{Al}$ was selected as a reference element due to its high concentration in the crustal earth and soils. The elemental concentrations in the earth crust used in this work are those published by Rudnick and Fountain in 1995. ${ }^{22}$

Enrichment factors close to unity show that the element, $\mathrm{Pb}$ in this case, is not enriched by additional sources and its origin is mainly natural. EF between 1 and 10 show that the contributions are natural and anthropogenic. When EF is higher than 10, the element is considered highly enriched and confirms that anthropogenic sources have contributed to its concentration. It is observed that all samples (Fig. 1) show EF higher than 10 indicating that $\mathrm{Pb}$ is enriched and confirming the anthropogenic origin of this element. While in the first sampling campaign, 2001-2002, 47\% of the samples had EF higher than 100, this percentage slightly increased to $53 \%$ in the second one, 20032004. Because not only local emission sources affect lead air pollution but also long-range atmospheric transport, five-days air mass backward trajectories were calculated using the NOAA HYSPLIT model version 4.8. The air mass transport pathways arriving at the sampling point at 9:00h were investigated according to the vertical velocity model. The heights of the backward air trajectories were 100, 500 and $1000 \mathrm{~m}$ over the surface. A classification according to air mass backward trajectories origin ${ }^{23}$ was performed for EF higher than 100 . It was found that in the first sampling, with the exception of $14 \%$ of the

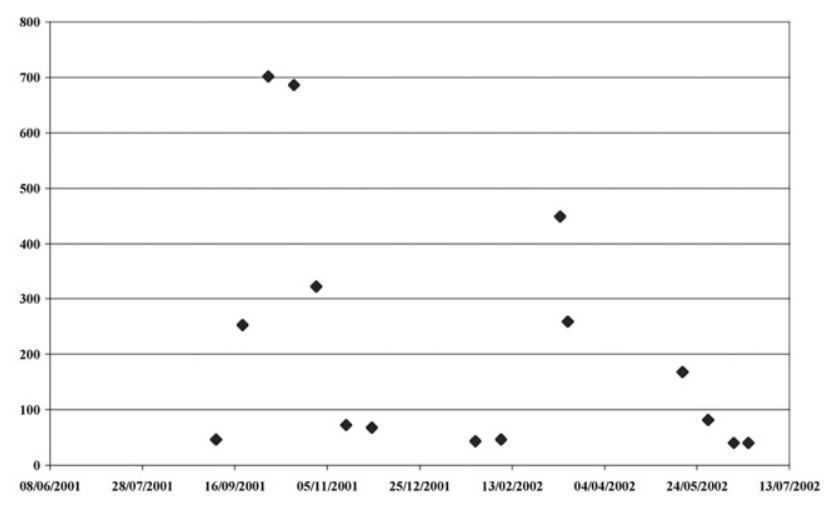

a)

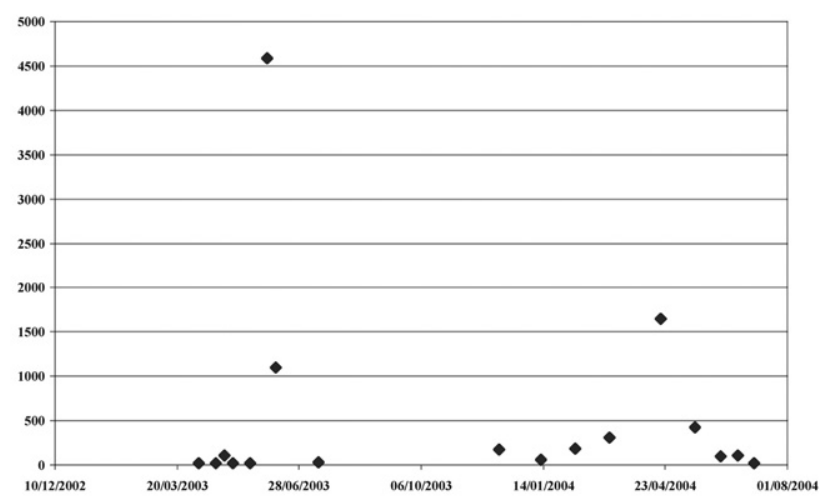

b)

Fig. 1 Enrichment factors (EF) for samples of the a) first and b) second campaigns. samples with Atlantic origin (AN/ANW), the rest were influenced by European countries (14\%), by the Mediterranean area (MED) (14\%) and by regional circulation (REG) (57\%). In the case of the second sampling, $22 \%$ of these samples had European origin, $11 \%$ REG, $11 \%$ MED, $11 \%$ AFR (North Africa) and $44 \%$ ANW. This indicated that, not only local emission sources but also the emissions from other countries in Europe and the Mediterranean area, could contribute to high $\mathrm{Pb}$ concentrations in Zaragoza atmosphere.

\subsection{Lead isotope ratios}

In this work, the lead isotope ratios for those samples in which the $\mathrm{Pb}$ concentration was higher than the quantification limit by ICP-OES, it means, 47 samples ( 24 from the first campaign and 23 from the second), were analysed. To determine the main $\mathrm{Pb}$ sources in the particulate matter is necessary to know the isotopic signature of each possible source impacting on a certain place. Such signature depends on the mineral characteristics of the soil or the material from which industrial $\mathrm{Pb}$ was extracted. ${ }^{5}$ These characteristics depend on the geographical area in which the study is carried out and ideally the lead isotope ratios for each type of source should be measured. That is not always possible and as an alternative, bibliography reporting these data must be used.

The values obtained for the lead isotope ratios were similar to those found in the literature for countries from the Northern Hemisphere. The ${ }^{206} \mathrm{~Pb} /{ }^{207} \mathrm{~Pb}$ and ${ }^{208} \mathrm{~Pb} /{ }^{207} \mathrm{~Pb}$ are comparable to those found by Bollhöfer et al. ${ }^{3}$ (2001) in some cities like Davis (USA), Cheng Du (China), Venice (Italy) and Moscow (Russia). On the other hand, those found in some French cities like Grenoble, Montpellier, Paris, Chateauneuf and Avignon are lower: 1.105-1.142 (2.381-2.408). Also compared with studies carried out in Madrid (1.097-(2.372)) and Valencia (1.114-1.128 (2.3852.405)) in 1994 and 1999, respectively, the isotopic compositions were lower than the ones found in Zaragoza for 2003-2004.

$\mathrm{Pb}-\mathrm{Pb}$ diagrams, in which two average isotope ratios are compared, were represented with the aim of analysing, interpreting and comparing data. In this work, it has been used to plot the difference between ${ }^{208} \mathrm{~Pb} /{ }^{207} \mathrm{~Pb}$ and the ${ }^{206} \mathrm{~Pb} /{ }^{207} \mathrm{~Pb}$ ratios. Fig. 2 shows the $\mathrm{Pb}-\mathrm{Pb}$ diagram of the sources used in this work: natural sources or geogenic, industrial, waste incineration, North African episodes and leaded-gasoline. As commented, the

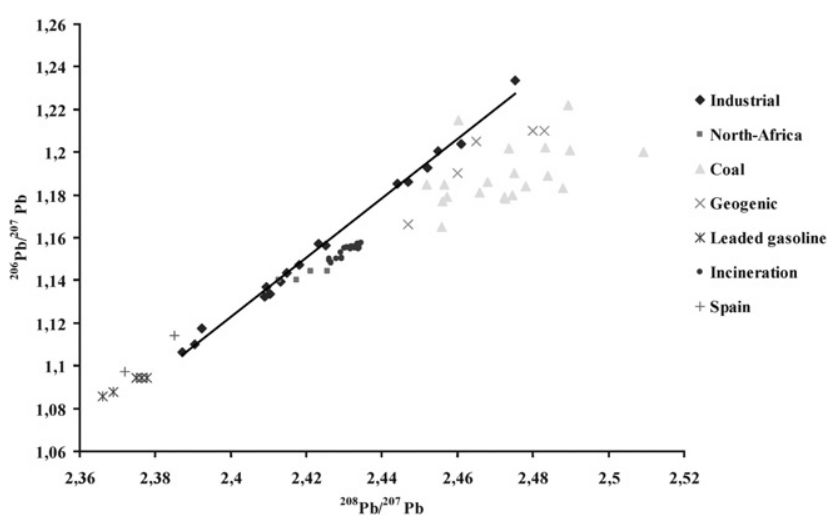

Fig. $2 \mathrm{~Pb}-\mathrm{Pb}$ diagram of sources according to the lead isotope ratios. 
environmental lead sources are varied and in order to use the isotopic fingerprint as discriminative tool it is necessary that the ratios between isotopes of each source are different. In general, rock and non polluted soils (normally associated with silicates and ferrous oxides) contain low concentrations of this metal (10-20 mg kg-1). Its isotopic composition is varied but normally it is concentrated in a range of high ${ }^{208} \mathrm{~Pb} /{ }^{207} \mathrm{~Pb}$ and ${ }^{206} \mathrm{~Pb} /{ }^{207} \mathrm{~Pb}$ ratios. The hircine granite, belt expanding from Marruecos to France along Spain and Portugal show ratios 1.19-1.21 (2.46-2.48), while pyrite from the Iberian Peninsula is in the range 1.1607-1.1661 (2.4402-2.4469). ${ }^{24-26}$

The lead isotope ratios of the European coals, in which the Spanish ones are included and with variable $\mathrm{Pb}$ concentrations, also seem to be quite uniform, in the range of 1.13-1.21 (2.43-2.475). ${ }^{27,28}$ Despite this is a potential $\mathrm{Pb}$ source for the anthropogenic $\mathrm{Pb}$ in the atmosphere, from the isotopic point of view, it is difficult to distinguish when comparing with natural sources and they are considered, all together, with the name of geogenic sources. ${ }^{25}$

The emissions associated with industrial processes show a high variability grade in its isotope ratios. ${ }^{29,30}$ Hack et al. ${ }^{25}$ (2002) showed that European emissions from different vehicle samples, diesel as well as gasoline (without $\mathrm{Pb}$ ), car batteries, metallurgic plants and melting industries could be represented by the known term "industrial lead line" which represents a blend of different materials from Canadian deposits and from the Mississippi Valley.

Waste incineration is also another potential lead pollution source because it can reach concentrations of $1000 \mathrm{mg} \mathrm{kg}^{-1}$. The isotopic composition for this source seems not to vary very much among the European countries and it is in the range $1.1427-1.1576(2.4260-2.4346){ }^{25,30,31}$

The dust intrusion from North African episodes in snow samples and rainwater in Central Europe has been remarked in the literature. ${ }^{32}$ The lead isotopic composition in the air masses from the dessert is influenced by industrial emissions and traffic (Morocco, Algeria, Tunisia and Western Sahara still use leaded-gasoline) because this metal, when its origin is anthropogenic, is associated with the finest particles, that are able to travel long distances. ${ }^{6}$ The lead isotope ratios for the anthropogenic emissions in that geographic area, seem to distribute in a narrow range around $1.14(2.42),{ }^{31}$ conforming a differentiable domain.

Some of the samples taken during the first sampling coincide with the last period in which leaded-gasoline was used in Spain (the commercialization finished in August 2001 but its use was permitted until the end of that year). In addition, it is also necessary to consider the chance that $\mathrm{Pb}$ from traffic is deposited and re-suspended afterwards by wind or by vehicles. In the whole of Europe, the lead isotope ratios in the leaded-gasoline are relatively narrow due to the main company which was producing tetramethyl and tetraethyl lead was the Associated Octel UK. In France, as well as in Spain, the company provided antiknock agents of Australian (80\%) and Moroccan (20\%) mines. The ratios calculated according to these percentages are in agreement with the average experimental values found in the South of France and Madrid in 1994 under the main influence of gasoline in the total $\mathrm{Pb}$ concentration and these have been used in this work. ${ }^{3,31}$

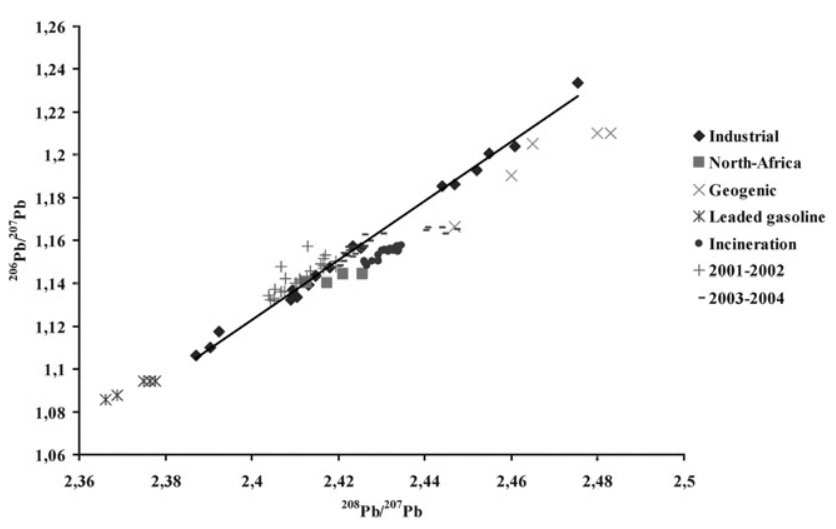

Fig. $3 \mathrm{~Pb}-\mathrm{Pb}$ diagram according to the lead isotope ratios for samples taken in Zaragoza.

Fig. 3 shows the lead isotope ratios in the $\mathrm{PM}_{10}$ for the different sampling dates. It can be observed that the lead isotope ratios for both samplings show differences. The first sampling seems to be characterized by lower isotope ratios than the second one and the points are located slightly on the industrial $\mathrm{Pb}$ line. For the second sampling and with the exception of a small group of dates, the rest are distributed along the industrial $\mathrm{Pb}$ line, indicating that the sampling point is influenced by the sources used to define the industrial line. For any of the two samplings, there was not any significant statistically seasonal variation.

In 2001 April, the $28.5 \%$ of the used gasoline contained lead. The lead isotope ratios for this fuel are lower than the industrial sources, therefore, in the first sampling, the lead from traffic had more influence in the $\mathrm{PM}_{10}$ than in the second sampling. Nevertheless, in the first sampling, such influence is not dominant and the lead present in the particulate matter results in a mixture of lead from traffic and industry. The influence of traffic factor in the second sampling is remarkable lower, giving as a result higher isotopic ratios. The average values for both samplings were $1.1424 \pm 0.0072(2.4209 \pm 0.0051)$ and $1.5748 \pm 0.0052(2.4227 \pm$ $0.0086)$.

If the $\mathrm{Pb}$ concentration in the atmosphere during the first sampling is considered as a mixture between the one coming from the gasoline and from the industry, the equation 2 can be used as representation of a binary mixture of both sources: ${ }^{33}$

$$
\mathrm{R}_{\mathrm{PM}_{10}}=\mathrm{R}_{\text {gasoline }} \mathrm{X}_{\text {gasoline }}+\mathrm{R}_{\text {industry }} \mathrm{X}_{\text {industry }}
$$

Where $\mathrm{R}_{\mathrm{PM}_{10}}$ are the ${ }^{206} \mathrm{~Pb} /{ }^{207} \mathrm{~Pb}$ ratios for $\mathrm{PM}_{10}$ samples and $\mathrm{R}_{\text {gasoline }}$ and $\mathrm{R}_{\text {industry }}$ are the average values of the ${ }^{206} \mathrm{~Pb} /{ }^{207} \mathrm{~Pb}$ for lead gasoline and industrial $\mathrm{Pb}$.

$\mathrm{X}_{\text {gasoline }}$ represents the contribution of the $\mathrm{Pb}$ coming from gasoline in the particulate matter and $1-X_{\text {gasoline }}\left(=X_{\text {industrial }}\right)$ represents the contribution of industrial $\mathrm{Pb}$ in samples. Because $\mathrm{R}_{\text {gasoline }}$ and $\mathrm{R}_{\text {industry }}$ are average values, the obtained results are approximated.

The average value after applying the equation 2 to samples taken during the first campaign 2001-2002 was $0.23 \pm 0.09$ $(23 \pm 9 \%)$. However, for the second campaign, the gasoline contribution was insignificant. These results are in agreement with different studies carried out in atmospheric samples in the whole world during long time periods with the aim of evaluating 
the $\mathrm{Pb}$ influence in the gasoline before and after its prohibition. In general, it is observed that samples were mainly influenced by traffic during the first part of 1990, with a mixed influence on traffic-industry during the period 1995-1999 and finally, almost industrial from 2000 . $^{5,34,35}$

In the Zaragoza $\mathrm{PM}_{10}$, a remarkable change is observed for a short period of time, probably due to the sampling site being close to a highway and it is influenced by traffic. Despite leadedgasoline being forbidden in Spain from 1st January 2002, part of it could be deposited on the road sides and gradually re-suspended by vehicles and wind. Some studies carried out in France $^{36}$ showed that lichens close to roads still contained the influence of traffic despite two years of leaded gasoline prohibition. However, the residence time of lead in urban dust is usually not greater than a year ${ }^{34}$ and therefore this influence is no longer observed in the samples taken during 2003-2004. Finally, when the sampling is carried out in a point very near to the highway and in a city like Zaragoza, in which the industrial weave is significant, the local pollution sources are clearly reflected. This is opposite to other studies carried out in locations not influenced directly by vehicle traffic or industrial sources ${ }^{8,32,37}$ in which it was possible to perceive episodes of transport coming from other locations.

Despite the lead isotope ratios in the samples of the second campaign being grouped around the lead industrial line, it is remarkable to say that there are five dates that seem to follow a different trend, grouping themselves to high isotope ratios outside the lead industrial line, between the dominion of the incineration of residues and the geogenic one. These samples are the ones corresponding to dates 9/6/03, 8/3/04, 19/4/04, 17/5/04 and $7 / 6 / 04$. For them, the concentrations of $\mathrm{Pb}$ were the highest ones because they seemed to be influenced by the incineration of residues and a geogenic component. However, it is not possible to discern between the resuspension of the terrestrial crust and the coal combustion since the relations determining these two last sources are very similar.

\section{Conclusion}

The lead concentrations and its isotope ratios have been studied from 2001-2004 in the airborne $\mathrm{PM}_{10}$ of Zaragoza in order to ascertain the main lead sources and the effectiveness of the nonleaded fuel normative. It has been found that a non statistically significant decrease in average concentrations of lead was observed in Zaragoza samples with predominance of anthropogenic sources manifested by the enrichment factors.

The ICP-QMS parameters have been optimized in order to measure the lead isotope ratios obtaining good results regarding precision ( $\mathrm{RSD}<0.1 \%$ for all isotopes) with the advantage of involving less sample preparation, shorter data acquisition times and being more easily available than other more precise analytical techniques (TIMS, high-resolution ICP-MS).

The effectiveness of the leaded fuel policies has been proved in such a way that, while a contribution of traffic sources related to leaded-fuel was clearly manifested in the samples from 20012002, in the second sampling, the lead isotope ratios were mainly located in the lead industrial line, corroborating as well the predominance of anthropogenic sources.

\section{References}

1 Directive 2008/50/EC of the European Parliament and of the Council of 21 May 2008 on ambient air quality and cleaner air for Europe.

2 S. Facchetti, Acc. Chem. Res., 1989, 22, 370-374.

3 A. Bollhöfer and K. J. R. Rossman, Geochim. Cosmochim. Acta, 2001, 65, 1727-1740.

4 Directive 98/70/EC of the European Parliament and of the Council of 13 October 1998 related to the quality of petrol and diesel fuels and amending directive 93/12/EEC.

5 D. Widory, S. Roy, Y. Le Moullec, G. Goupil, A. Cocherie and C. Guerrot, Atmos. Environ., 2004, 38, 953-961.

6 P. Flament, M. L. Bertho, K. Deboudt, A. Véron and E. Puskaric, Sci. Total Environ., 2002, 296, 35-37.

7 G. Aberg, J. M. Pacyna, H. Stray and B. L. Skjelkvale, Atmos. Environ., 1999, 33, 3335-3344.

8 D. J. Bellis, K. Satake, M. Inagaki, J. Zeng and T. Oizumi, Sci. Total Environ., 2005, 341, 149-158.

9 W. Wang, X. Liu, L. Zhao, D. Guo, X. Tian and F. Adams, Sci. Total Environ., 2006, 364, 175-187.

10 J. M. López, M. S. Callén, R. Murillo, T. Garcia, M. V. Navarro, M. T. de la Cruz and A. M. Mastral, Environ. Res., 2005, 99, 58-67.

11 M. S. Callén, M. T. de la Cruz, J. M. López, R. Murillo, M. V. Navarro and A. M. Mastral, Water, Air, Soil Pollut., 2008, 190, $1-4$.

12 A. A. Vanheuzen, T. Hoekstra and B. Vanwingerden, J. Anal. At. Spectrom., 1989, 4, 483-489.

13 J. S. Becker, J. Anal. At. Spectrom., 2005, 20, 1173-1184.

14 M. Komarek, V. Ettler, V. Chrastny and M. Mihaljevic, Environ. Int., 2008, 34, 562-577.

15 P. Marzo, F. Laborda and J.-A. Perez-Arantegui, Atom. Spectrosc., 2007, 28, 195-201.

16 F. Monna, J. L. Loizeau, B. A. Thomas, C. Guéguen and P. Y. Favarger, Spectrochim. Acta, Part B, 1998, 53, 1317-1333.

17 Y. Qin and K. Oduyemi, Atmos. Environ., 2003, 37, 1799-1809.

18 V. Mugica, M. Maubert, M. Torres, J. Munoz and E. Rico, J. Aerosol Sci., 2002, 33, 91-102.

19 M. Abu-Allaban, A. W. Gertler and D. H. Lowenthal, Atmos. Environ., 2002, 36, 5549.

20 V. K. Mishra, K. H. Kim, C. H. Kang and K. C. Choi, Atmos. Environ., 2004, 38, 2653-2664.

21 R. Zhang, Z. Shen and H. Zou, Particuology, 2009, 7, 211-214.

22 R. L. Rudnick and D. M. Fountain, Rev. Geophys., 1995, 33, 267-309.

23 M. Viana, Niveles, composición y origen del material particulado atmosférico en los sectores Norte y Este de la Península Ibérica y Canarias, PhD Thesis, 2003, Universidad de Barcelona.

24 F. Elbaz-Poulichet, P. Holliger and J. M. Martin, Sci. Total Environ., 1986, 54, 61-76.

25 U. K. Haack, F. H. Gutsche, K. Plessow and H. Heinrichs, Water, Air, Soil Pollut., 2002, 139, 261-288.

26 M. E. Kylander, D. J. Weiss, A. M. Cortizas, B. Spiro, R. GarciaSanchez and B. J. Coles, Earth Planet. Sci. Lett., 2005, 240, 467485.

27 B. Kober, M. Wessels, A. Bollhöfer and A. Mangini, Geochim. Cosmochim. Acta, 1999, 63, 1293-1303.

28 M. Díaz-Somoano, I. Suárez-Ruiz, J. I. G. Alonso, J. Ruiz Encinar, M. A. López-Antón and M. R. Martínez-Tarazona, Int. J. Coal Geol., 2007, 71, 28-36.

29 A. Veron, P. Flament, M. L. Bertho, L. Alleman, R. Flegal and B. Hamelin, Atmos. Environ., 1999, 33, 3377-3388.

30 J. Carnigan, G. Libourel, C. Cloquet and L. Le Forestier, Environ. Sci. Technol., 2005, 39, 2018-2024.

31 A. M. Veysseyre, A. F. Bollhöfer, K. J. R. Rosman, C. P. Ferrari and C. F. Boutron, Environ. Sci. Technol., 2001, 35, 4463-4469.

32 J. M. Luck and D. Ben Othman, Chem. Geol., 2002, 182, 443-460.

33 P. Flament, K. Deboudt, M. Bertho, A. Veron and E. Puskaric, J. Phys. IV, 2003, 107, 487-490.

34 F. Monna, J. Lancelot, I. W. Croudace, A. B. Cundy and J. T. Lewis, Environ. Sci. Technol., 1997, 31, 2277-2286.

35 J. Zheng, M. Tan, Y. Shibata, A. Tanaka, Y. Li, G. Zhang, Y. Zhang and Z. Shan, Atmos. Environ., 2004, 38, 1191-1200.

36 C. Cloquet, J. Carignan and G. Libourel, Atmos. Environ., 2006, 40, 574-587.

37 C. S. L. Lee, X. D. Li, G. Zhang, J. Li, A. J. Ding and T. Wang, Atmos. Environ., 2007, 41, 432-447. 